Vol 1 No 22020 Desember 2020

Jurnal AlphaEuclidEdu

Received: 25/11/2020; Revised: 30/11/2020; Accepted: 08/12/2020

\title{
TINGKAT KEPUASAN MAHASISWA TERHADAP LAYANAN BIMBINGAN TUGAS AKHIR
}

\author{
$\mathbf{1}_{\text {Asep Nursangaji, }}{ }^{2}$ Hamdani \\ ${ }^{1,2}$ Pendidikan Matematika FKIP Universitas TanjungpuraUNTAN Pontianak \\ Email: nursangaji@yahoo.com
}

\begin{abstract}
Nowadays, there are several universities in West Kalimantan that have mathematics education department, such as IKIP Pontianak, STKIP Singkawang, and STKIP Sintang. This condition provides great opportunities for prospective students who want to become mathematics teachers in schools, especially high schools. On the other side, the presence of mathematics education department in several universities in West Kalimantan is a challenge for Mathematics Education department FKIP Untan. One of the challenges that come is how to produce graduates who can compete in the world of work. In order to create qualified mathematics teacher candidates, it is very important for the FKIP Untan mathematics education department to provide one of the quality final assignment guidance services so that final year students can have quality final projects. This study will examine how high the level of student satisfaction with final assignment guidance services in Mathematics Education Department FKIP Untan. Furthermore, it will be known what service items should be improved and developed in an effort to increase student satisfaction. The level of student satisfaction with the final assignment guidance service is $0 \%$ of students are not satisfied, $0 \%$ of students are not satisfied, 9\% of students are satisfied, 30\% of students are quite satisfied, and $61 \%$ of students are very satisfied. It can be concluded that the final year students of the Mathematics Education Department, Teaching and Education Faculty, Tanjungpura University are satisfied with the services provided by the supervisors

Keywords: Satisfaction; academic services; final assignment guidance.
\end{abstract}

\section{Pendahuluan}

Perguruan Tinggi sebagai salah satu lembaga pendidikan pada dasarnya adalah organisasi jasa, yakni memberikan layanan pendidikan pada masyarakat. Sebagai organisasi jasa, Perguruan Tinggi dituntut untuk memberikan pelayanan yang terbaik kepada pelanggan, khususnya kepada mahasiswa karena akan mempengaruhi kualitas lulusan yang dihasilkan. Fakultas Keguruan dan Ilmu Pendidikan (FKIP) Untan sebagai salah satu organisasi layanan publik, tentu juga memiliki tantangan yang sama dengan FKIP/lembaga Kependidikan Perguruan Tinggi lainnya. FKIP mengalami kondisi persaingan yang sama sehingga harus memikirkan strategi peningkatan kualitas pelayanan yang memberi kepuasan kepada mahasiswanya.Sejauh ini, Prodi Pendidikan Matematika FKIP UNTAN telah berusaha semaksimal mungkin untuk memberikan layanan akademik kepada mahasiswa sebagai konsumennya. Karena pelayanan akademik yang berkualitas akan menciptakan lulusan/mahasiswa yang berkualitas sehingga mampu bersaing di era globailsasi/ era revolusi industri 4.0. Layanan akademik tersebut, seperti: perkuliahan, kurikulum, bimbngan/konsultasi akademik, praktikum, bimbingan tugas akhir, dan lain-lain (Tampubolon, 2001). Salah satu indeks penilaian kepuasan mahasiswa dalam layanan akademik di FKIP Universitas Tanjungpura adalah bimbingan penulisan tugas akhir. Dalam kehidupan perkuliahan, setiap mahasiswa pasti diberikan dosen pembimbing seminar dan skripsi yang berfungsi sebagai penunjuk arah menulis tugas akhir sebagai syarat untuk mendapatkan gelar sarjana pendidikan.. Dari indeks tersebut tentunya harus diperhatikan aspek kemudahan dan kenyamanan interaksi antara mahasiswa sebagai 
Vol 1 No 22020 Desember 2020

Jurnal AlphaEuclidEdu

Received: 25/11/2020; Revised: 30/11/2020; Accepted: 08/12/2020

stakeholder dan dosen sebagai penyedia layanan, sehingga dapat dihasilkan sebuah produk ilmiah yang berkualitas.

\section{Metode Penelitian}

\section{Pendekatan Penelitian}

Penelitian ini menggunakan Pendekatan kuantitatif dengan metode deskriptif. penggunaan metode deskriptif bertujuan untuk menggambarkan secara jelas tentang kepuasan mahasiswa terhadap kualitas layanan akademik pada prodi pendidikaan matematika FKIP Untan tahun akademik 2019/2020. Bentuk penelitian yang digunakan adalah survey studies.

\section{Waktu dan Tempat Penelitian}

Penelitian ini berlokasi di Prodi Pendidikan Matematika FKIP UNTAN, yang dilakukan pada bulan Mei - Oktober 2020

\section{Populasi dan Sampel}

Populasi dalam penelitian ini adalah mahasiswa tingkat akhir Prodi Pendidikan Matematika FKIP Untan untuk data kepuasan layanan bimbingan tugas akhir. Pembatasan tersebut dimaksudkan untuk menjaring mahasiswa yang telah benar-benar merasakan layanan bimbingan tugas akhir, sehingga mereka bisa menilai tingkat kepuasan serta tingkat urgensi dari pelayanan tersebut

Untuk pengambilan sampel survei, peneliti menggunakan probability sampling, yaitu teknik pengambilan sampel yang memberikan peluang yang sama bagi setiap unsur (anggota) populasi untuk dipilih menjadi anggota sampel, dan teknik yang dipilih adalah proportionate random sampling, yaitu pengambilan anggota sampel dilakukan dengan memperhatikan proporsi yang ada dalam populasi itu.

Analisis Data

Analisis data menggunakan analisis deskriptif dengan mencari rata-rata tingkat kepuasan mahasiswa untuk masing-masing dimensi dan secara umum kemudian dibuat interval. Rentang tersebut akan digunakan sebagai dasar kriteria tingkat kepuasan mahasiswa.

\section{Hasil dan Pembahasan}

\section{Tingkat Kepuasan Mahasiswa Terhadap Aspek - Aspek Layanan Bimbingan} Akademik

\section{Aspek Availabilitas}

Kepuasan mahasiswa terhadap layanan bimbingan tugas akhir pada aspek availabilitas diukur dengan 4 pernyataan dengan 5 tingkat kepuasan. 5 tingkat kepuasan yang digunakan adalah tidak puas, kurang puas, puas, cukup puas, dan sangat puas. Berdasarkan hasil analisis data kuisioner yang diisi oleh 150 mahasiswa sebagai responden, didapatkan data tingkat kepuasan mahasiswa terhadap layanan bimbingan akademik yang ditunjukan dalam gambar 1 . 
Vol 1 No 22020 Desember 2020

Jurnal AlphaEuclidEdu

Received: 25/11/2020; Revised: 30/11/2020; Accepted: 08/12/2020

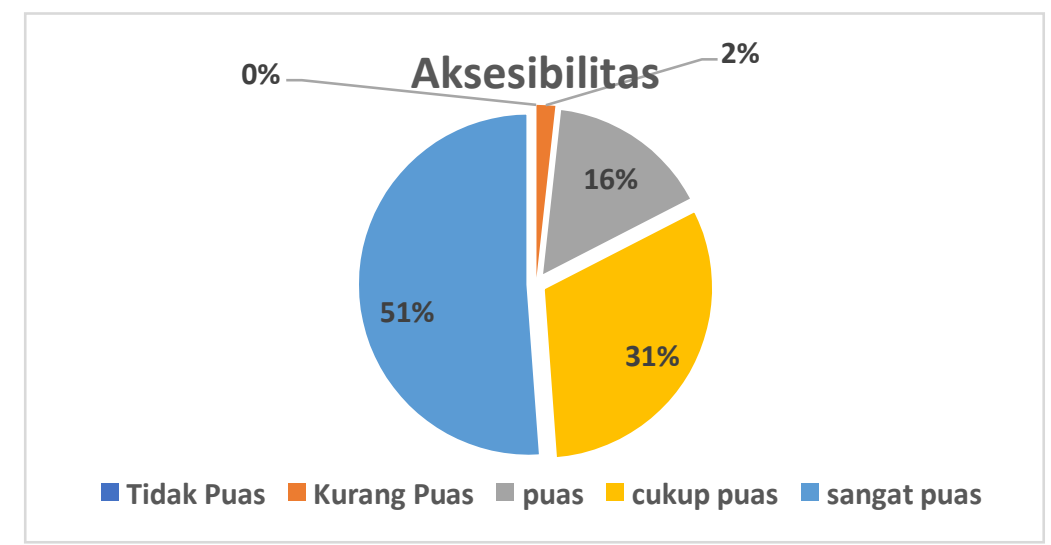

Gambar 1. Diagram tingkat kepuasan mahasiswa terhadap layanan bimbingan tugas akhir aspek availabilitas

Berdasarkan diagram di atas, dari 150 mahasiswa, sebanyak 0 mahasiswa merasa tidak puas, 3 mahasiswa merasa kurang puas, 24 mahasiswa merasa puas, 47 mahasiswa merasa cukup puas, dan 77 mahasiswa merasa sangat puas dengan layanan bimbingan tugas akhir yang diberikan oleh para dosen yang bertupoksi sebagai dosen pembimbing skripsi di Program Studi Pendidikan Matematika Fakultas Keguruan dan Ilmu Pendidikan Universitas Tanjungpura

\section{Aspek Penguasaan Materi}

Kepuasan mahasiswa terhadap layanan bimbingan tugas akhir pada aspek penguasaan materi diukur dengan 6 pernyataan dengan 5 tingkat kepuasan. 5 tingkat kepuasan yang digunakan adalah tidak puas, kurang puas, puas, cukup puas, dan sangat puas. Berdasarkan hasil analisis data kuisioner yang diisi oleh 150 mahasiswa sebagai responden, didapatkan data tingkat kepuasan mahasiswa terhadap layanan bimbingan akademik yang ditunjukan dalam gambar 2 .

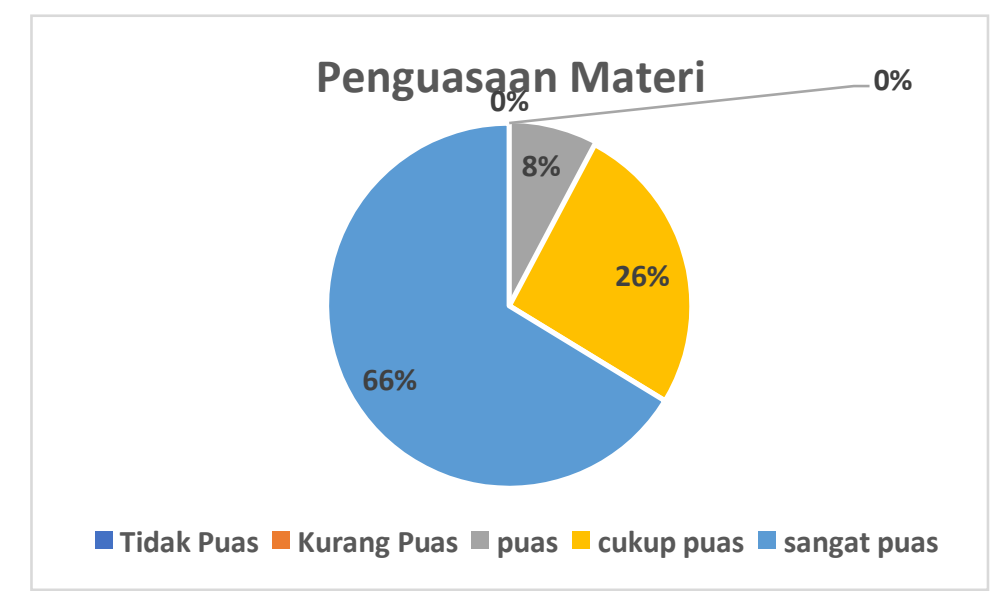

Gambar 2. Diagram tingkat kepuasan mahasiswa terhadap layanan bimbingan tugas akhir aspek penguasaan materi 
Vol 1 No 22020 Desember 2020

Jurnal AlphaEuclidEdu

Received: 25/11/2020; Revised: 30/11/2020; Accepted: 08/12/2020

Berdasarkan diagram di atas, dari 150 mahasiswa, sebanyak 0 mahasiswa merasa tidak puas, 0 mahasiswa merasa kurang puas, 12 mahasiswa merasa puas, 39 mahasiswa merasa cukup puas, dan 99 mahasiswa merasa sangat puas dengan layanan bimbingan tugas akhir aspek penguasan materi yang diberikan oleh para dosen yang bertupoksi sebagai dosen pembimbing skripsi di Program Studi Pendidikan Matematika Fakultas Keguruan dan Ilmu Pendidikan Universitas Tanjungpura

\section{Aspek Proses bimbingan}

Kepuasan mahasiswa terhadap layanan bimbingan tugas akhir pada aspek proses bimbingan diukur dengan 10 pernyataan dengan 5 tingkat kepuasan. 5 tingkat kepuasan yang digunakan adalah tidak puas, kurang puas, puas, cukup puas, dan sangat puas. Berdasarkan hasil analisis data kuisioner yang diisi oleh 150 mahasiswa sebagai responden, didapatkan data tingkat kepuasan mahasiswa terhadap layanan bimbingan akademik yang ditunjukan dalam gambar 3 .

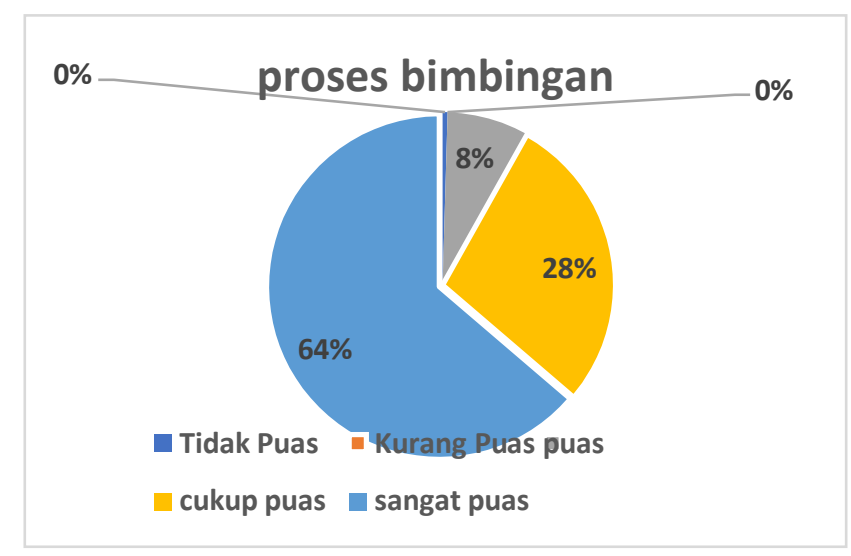

Gambar 3. Diagram tingkat kepuasan mahasiswa terhadap layanan bimbingan tugas akhir aspek proses bimbingan

Berdasarkan diagram di atas, dari 150 mahasiswa, sebanyak 0 mahasiswa merasa tidak puas, 0 mahasiswa merasa kurang puas, 12 mahasiswa merasa puas, 42 mahasiswa merasa cukup puas, dan 96 mahasiswa merasa sangat puas dengan layanan bimbingan tugas akhir aspek proses bimbingan yang diberikan oleh para dosen yang bertupoksi sebagai dosen pembimbing skripsi di Program Studi Pendidikan Matematika Fakultas Keguruan dan Ilmu Pendidikan Universitas Tanjungpura

\section{Aspek Proses Penyelesaian}

Kepuasan mahasiswa terhadap layanan bimbingan tugas akhir pada aspek proses bimbingan diukur dengan 10 pernyataan dengan 5 tingkat kepuasan. 5 tingkat kepuasan yang digunakan adalah tidak puas, kurang puas, puas, cukup puas, dan sangat puas. Berdasarkan hasil analisis data kuisioner yang diisi oleh 150 mahasiswa sebagai responden, didapatkan data tingkat kepuasan mahasiswa terhadap layanan bimbingan akademik yang ditunjukan dalam gambar 4 . 
Vol 1 No 22020 Desember 2020

Jurnal AlphaEuclidEdu

Received: 25/11/2020; Revised: 30/11/2020; Accepted: 08/12/2020

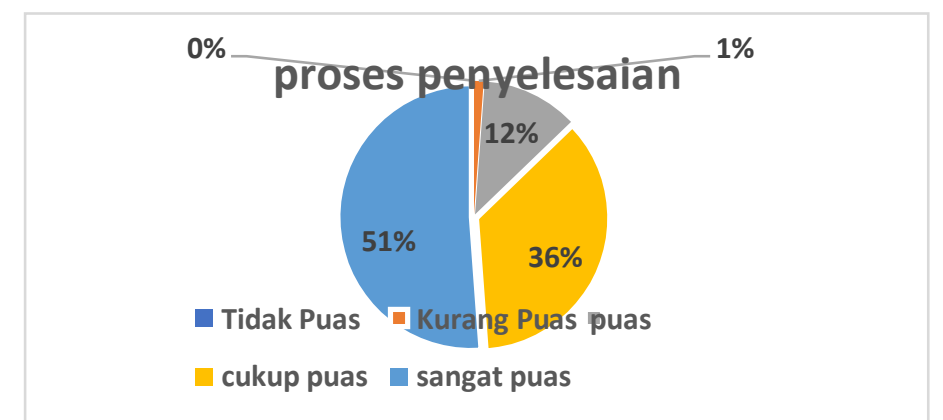

Gambar 4. Diagram tingkat kepuasan mahasiswa terhadap layanan bimbingan tugas akhir aspek proses penyelesaian

Berdasarkan diagram di atas, dari 150 mahasiswa, sebanyak 0 mahasiswa merasa tidak puas, 2 mahasiswa merasa kurang puas, 18 mahasiswa merasa puas, 53 mahasiswa merasa cukup puas, dan 77 mahasiswa merasa sangat puas dengan layanan bimbingan tugas akhir aspek proses penyelesaian yang diberikan oleh para dosen yang bertupoksi sebagai dosen pembimbing skripsi di Program Studi Pendidikan Matematika Fakultas Keguruan dan Ilmu Pendidikan Universitas Tanjungpura.

\section{Aspek Feedback dan Komentar}

Kepuasan mahasiswa terhadap layanan bimbingan tugas akhir pada aspek proses bimbingan diukur dengan 2 pernyataan dengan 5 tingkat kepuasan. 5 tingkat kepuasan yang digunakan adalah tidak puas, kurang puas, puas, cukup puas, dan sangat puas. Berdasarkan hasil analisis data kuisioner yang diisi oleh 150 mahasiswa sebagai responden, didapatkan data tingkat kepuasan mahasiswa terhadap layanan bimbingan akademik yang ditunjukan dalam gambar 5 .

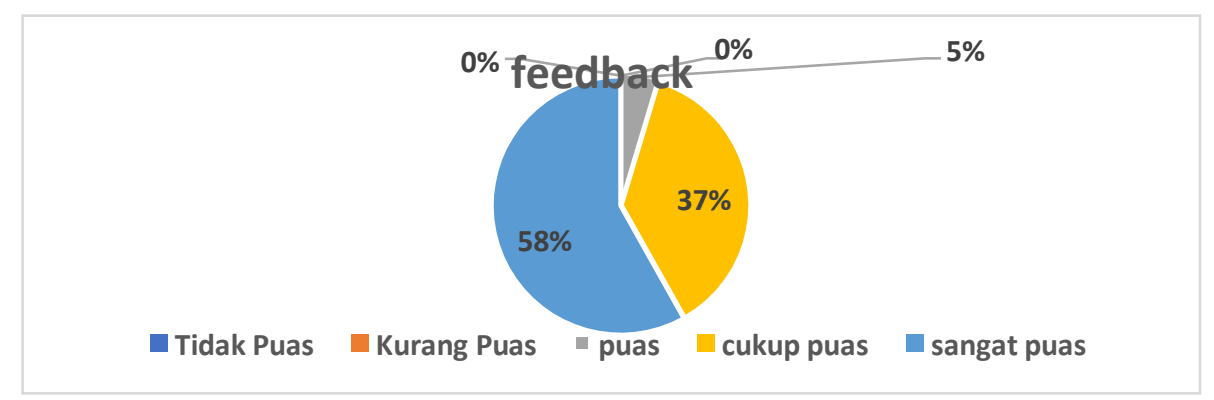

Gambar 5. Diagram tingkat kepuasan mahasiswa terhadap layanan bimbingan tugas akhir aspek feedback

Berdasarkan diagram di atas, dari 150 mahasiswa, sebanyak 0 mahasiswa merasa tidak puas, 0 mahasiswa merasa kurang puas, 8 mahasiswa merasa puas, 56 mahasiswa merasa cukup puas, dan 86 mahasiswa merasa sangat puas dengan layanan bimbingan tugas akhir aspek proses penyelesaian yang diberikan oleh para dosen yang bertupoksi sebagai dosen pembimbing skripsi di Program Studi Pendidikan Matematika Fakultas Keguruan dan Ilmu Pendidikan Universitas Tanjungpura 
Vol 1 No 22020 Desember 2020

Jurnal AlphaEuclidEdu

Received: 25/11/2020; Revised: 30/11/2020; Accepted: 08/12/2020

Kepuasan Mahasiswa Pada Layanan Bimbingan Tugas Akhir ( Data seluruh aspek)

Kepuasan mahasiswa terhadap layanan bimbingan tugas akhir diukur dengan seluruh pertanyaan kuisioner dengan 5 tingkat kepuasan. 5 tingkat kepuasan yang digunakan adalah tidak puas, kurang puas, puas, cukup puas, dan sangat puas. Berdasarkan hasil analisis data kuisioner yang diisi oleh 150 mahasiswa sebagai responden, didapatkan data tingkat kepuasan mahasiswa terhadap layanan bimbingan akademik yang ditunjukan dalam gambar 6 .

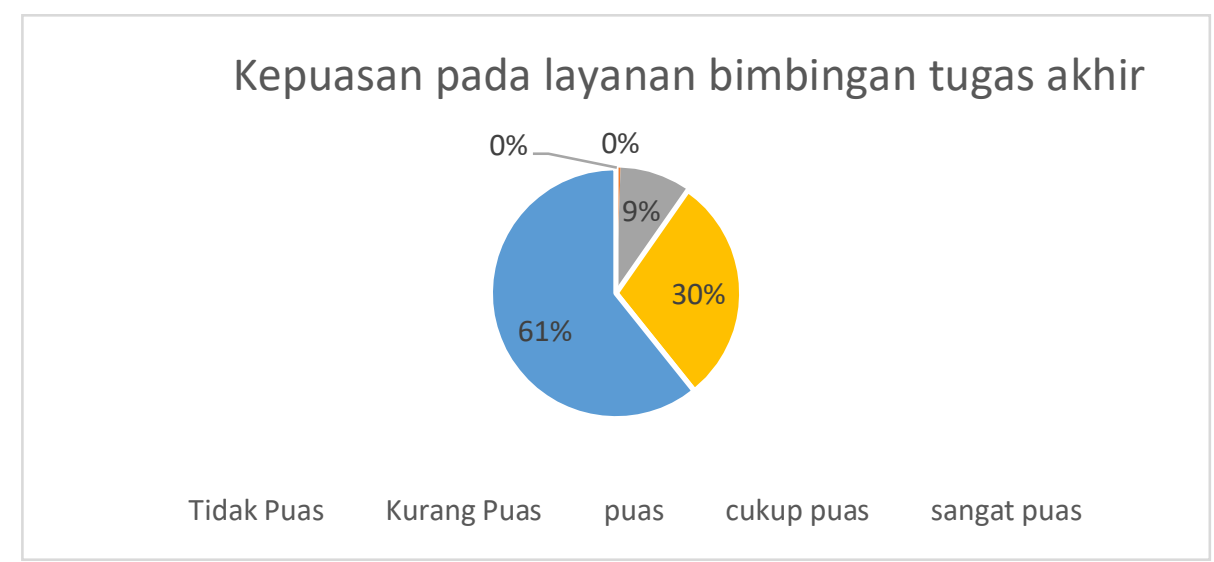

Gambar 6. Diagram tingkat kepuasan mahasiswa terhadap layanan bimbingan tugas akhir (data seluruh aspek)

Berdasarkan diagram di atas, dari 150 mahasiswa, sebanyak 0 mahasiswa merasa tidak puas, 0 mahasiswa merasa kurang puas, 14 mahasiswa merasa puas, 45 mahasiswa merasa cukup puas, dan 51 mahasiswa merasa sangat puas dengan layanan bimbingan tugas akhir yang diberikan oleh para dosen yang bertupoksi sebagai dosen pembimbing skripsi di Program Studi Pendidikan Matematika Fakultas Keguruan dan Ilmu Pendidikan Universitas Tanjungpura

\section{Pembahasan}

Berdasarkan analisis data kuisioner yang dilakukan dengan menghitung sebaran skor di setiap distribusi frekuensi kemudian diinterpretasikan dengan kriteria persentase, Pada aspek availabilitas dari 150 mahasiswa, tidak ada mahasiswa yang merasa tidak puas, $2 \%$ mahasiswa merasa kurang puas, $16 \%$ mahasiswa merasa puas, $31 \%$ mahasiswa merasa cukup puas, dan 51\% mahasiswa merasa sangat puas. Kemudian pada aspek penguasaan materi, dari 150 mahasiswa, tidak ada mahasiswa yang merasa tidak puas dan kurang puas, $8 \%$ mahasiswa merasa puas, 26\% mahasiswa merasa cukup puas, dan $66 \%$ mahasiswa merasa sangat puas. Pada aspek proses bimbingan, dari 150 mahasiswa, tidak ada mahasiswa yang merasa tidak puas dan kurang puas, $8 \%$ mahasiswa merasa puas, $28 \%$ mahasiswa merasa cukup puas, dan $64 \%$ mahasiswa merasa sangat puas. Lalu pada aspek proses penyelesaian, dari 150 mahasiswa, tidak ada mahasiswa yang merasa tidak puas, $1 \%$ mahasiswa merasa kurang puas, $12 \%$ mahasiswa merasa puas, $36 \%$ mahasiswa merasa cukup puas, dan 
Vol 1 No 22020 Desember 2020

Jurnal AlphaEuclidEdu

Received: 25/11/2020; Revised: 30/11/2020; Accepted: 08/12/2020

51\% mahasiswa merasa sangat puas. Pada aspek feedback, dari 150 mahasiswa, tidak ada mahasiswa yang merasa tidak puas dan kurang puas, $5 \%$ mahasiswa merasa puas, $37 \%$ mahasiswa merasa cukup puas, dan $58 \%$ mahasiswa merasa sangat puas.

Dari data 5 aspek tersebut di dapatkan data yang menunjukan tingkat kepuasan mahasiswa terhadap layanan bimbingan tugas akhir yang diberikan oleh para dosen yang bertupoksi sebagai dosen pembimbing skripsi di Program Studi Pendidikan Matematika Fakultas Keguruan dan Ilmu Pendidikan UniversitasTanjungpura, dari 150 mahasiswa, tidak ada mahasiswa yang merasa tidak puas dan kurang puas, 9\% mahasiswa merasa puas, $30 \%$ mahasiswa merasa cukup puas, dan $61 \%$ mahasiswa merasa sangat puas.

Secara umum, indikator kepuasan layanan bimbingan tugas akhir dinilai sudah memuaskan dengan hasil kepuasan 100\% ( Puas hingga sangat puas). Artinya pelayanan bimbingan akademik yang diberikan oleh para dosen yang bertupoksi sebagai dosen pembimbing skripsi mahasiswa Program Studi Pendidikan Matematika Fakultas Keguruan dan Ilmu Pendidikan Universitas Tanjungpura sudah optimal. Namun apabila dilihat dari masing - masing aspek yang diukur, masih ada beberapa persen mahasiswa merasa kurang puas dengan layanan yang telah diberikan para dosen yang bertupoksi sebagai dosen pembimbing skripsi mahasiswa Program Studi Pendidikan Matematika Fakultas Keguruan dan Ilmu Pendidikan Universitas Tanjungpura. yaitu pada aspek availabilitas dan aspek proses penyelesiaan. Hal ini dapat terjadi karena beberapa factor seperti kegiatan dosen pembimbing skripsi yang dimungkinkan sedang padat, dan juga dimungkinkan hilangnya motivasi dari mahasiswa tingkat akhir untuk menyelesaikan naskahnya,

Untuk meminimalisir hal tersebut bisa diberlakukan perjanjian atau kontrak bimbingan antara dosen pembimbing skripsi dengan mahasiswa bimbinganya agar terjadwal untuk bertemu dan berkonsultasi, hal ini juga dapat meminimalisir hilangnya motivasi mahasiswa tuk menyelesaikan tulisannya karena proses bimbingannya berjalan secara rutin.

\section{Kesimpulan dan Saran Kesimpulan}

Tingkat kepuasan mahasiswa terhadap layanan bimbingan tugas akhir adalah $0 \%$ mahasiswa merasa tidak puas, $0 \%$ mahasiswa merasa kurang puas, 9\% mahasiswa merasa puas, $30 \%$ mahasiswa merasa cukup puas, dan $61 \%$ mahasiswa merasa sangat puas. Dapat disimpulkan bahwa mahasiswa tingkat akhir Program Studi Pendidikan Matematika Fakultas Keguruan dan Ilmu Pendidikan Universitas Tanjungpura puas atas layanan yang telah diberikan oleh dosen pembimbing.

Hal- hal yang harus diperbaiki untuk meningkatkan kepuasan mahasiswa terhadap layanan bimbingan tugas akhir adalah diberlakukan perjanjian atau kontrak bimbingan antara dosen pembimbing skripsi dengan mahasiswa bimbinganya agar 
Vol 1 No 22020 Desember 2020

Jurnal AlphaEuclidEdu

Received: 25/11/2020; Revised: 30/11/2020; Accepted: 08/12/2020

terjadwal untuk bertemu dan berkonsultasi, hal ini juga dapat meminimalisir hilangnya motivasi mahasiswa tuk menyelesaikan tulisannya karena proses bimbingannya berjalan secara rutin.

\section{Saran}

Perlu dilakukan tindak lanjut dari hasil penelitian ini sehingga dapat meningkatkan mutu layanan dan mutu sumber daya manusa di Program Studi Pendidikan Matematika Fakultas Keguruan dan Ilmu Pendidikan Universitas Tanjungpura.

\section{Referensi}

Buchari Alma. 2009. Pemasaran Jasa Pendidikan yang Fokus Pada Mutu, dalam Buchari Alma dan Ratih Hurriyati (ed.), ManajemenCorporate \& Strategi Pemasaran Jasa Pendidikan. Bandung: Alfabeta.

Elliot, K..; Shin, D. 1999. Assessing student satisfaction: an approach to help in the development of marketing strategy for a university. Marketing Management Association.

Jurkowitsch, Silke, et.al. 2006, A Student Satisfaction Model For Austrian Higher Education Providers Considering Aspects Of Marketing Communications, Special Edition On Consumer Satisfaction - Global Perspective, pp. 9-23.

Kotler, Philip. 1997. Manajemen Pemasaran, Analisis, Perencanaan, Implementasi dan Control Jilid I. Edisi-9. Jakarta: PT Prenhallindo

Mahmud, Marzuki. 2012. Manajemen Mutu Perguruan Tinggi. Jakarta: Rajawali Press.

Supranto, J.2006. Pengukuran Tingkat Kepuasan Pelanggan. Jakarta: Rieneka Cipta Tampubolon.

Daulat P. 2001. Perguruan Tinggi Bermutu. Jakarta: PT. Gramedia Pustaka Utama Tjiptono, Fandy. 1997. Strategi Pemasaran. Yogyakarta: Andi Offset.

Yamif, Zuliam. 2001. Manajemen Kualitas Produk. Yogyakarta: Ekonisia.

Zeithaml, V.A. dan Bitner, M.J. 2000. Services Marketing: Integrating Customer Focus Across the Firm. (United States of America: Irwin McGraw-Hill. 